\title{
GCU
}

Glasgow Caledonian

University

University for the Common Good

\section{The development of a framework for a design for safety BIM tool}

Hayne, Graham Richard; Kumar, Bimal; Hare, Billy

Published in:

Computing in Civil and Building Engineering (2014)

DOI:

$10.1061 / 9780784413616.007$

Publication date:

2014

Document Version

Author accepted manuscript

Link to publication in ResearchOnline

Citation for published version (Harvard):

Hayne, GR, Kumar, B \& Hare, B 2014, The development of a framework for a design for safety BIM tool. in Computing in Civil and Building Engineering (2014): Proceedings of the CIB W78 Conference. American Society of Civil Engineers (ASCE), pp. 49-56. https://doi.org/10.1061/9780784413616.007

\section{General rights}

Copyright and moral rights for the publications made accessible in the public portal are retained by the authors and/or other copyright owners and it is a condition of accessing publications that users recognise and abide by the legal requirements associated with these rights.

Take down policy

If you believe that this document breaches copyright please view our takedown policy at https://edshare.gcu.ac.uk/id/eprint/5179 for details of how to contact us. 


\section{The development of a framework for a design for safety BIM tool}

Graham Hayne, Bimal Kumar and Billy Hare

School of Engineering and Built Environment, Glasgow Caledonian University, Cowcaddens Road, Glasgow, G4 0BA.UK. Email: Graham.Hayne@gcu.ac.uk

Key words: Digital design. BIM. Design for safety. Digital visualization Abstract

The character of building design offices has changed dramatically following the widespread adoption of digital design, drawing and modelling. Simultaneously, there is a growing recognition that designers have a responsibility to produce designs with minimal hazards to constructors and operators of facilities. By revisiting the philosophy of engineering, science and design, the radical impact the digital world has upon the traditional working practices of consulting engineering is explored. Consideration is given to the consequences of these changes upon the training, knowledge acquisition and effectiveness of engineers to deliver hazard free designs.

Historically, engineers used approximations and rules of thumb to produce acceptable, if not optimum, designs. Hand calculations undertaken by engineers accorded them the ability to develop a 'feel' for the structure allowing 'rogue' results to be challenged and corrected.

Digital designs are produced so rapidly that the ability to gain experience can be severely impacted contributing to a blind acceptance of results. Combined with isolated working, minimal scope for collaboration exists leading to a sense of omniscience. The potential reduction in experiences of engineers raises questions about their ability to understand digital images and the ability to discern the pertinent issues.

This paper outlines work being undertaken which could potentially help in the development of digital design systems, including Building Information Modelling (BIM) tools, that could educate and disseminate design for safety (DfS) knowledge, both tacit and codified, which is currently in danger of being lost.

\section{Introduction}

The procedures and business models of the architecture, engineering and construction (AEC) industry are being radically transformed by introduction of BIM. The introduction of this process provides an opportunity for the industry to review and update its approach to the identification of hazards and management of health and safety (H\&S).

This discussion paper identifies the needs of the modern industry required to allow the successful execution of H\&S strategies. This is achieved by considering the philosophy of building engineering and design. The paper focuses on how the training and development of designers has changed following the widespread 
introduction of digital analysis and modelling tools. By analysing these changes and apparent shortcomings, suggestions are made for a framework for the design of a digital BIM based tool that could enhance the training and development of engineers and improve DfS.

\section{Background}

It is widely accepted that construction sites are dangerous work environments. The origin of hazards can be wide reaching but up to half of the construction accidents in the UK could have been mitigated through a design change (Haslam et al, 2005). Additionally, Gambatese and Hinze (1999) identified that designers are often not aware of their impact on site safety and lack the knowledge and ability to modify their designs to improve safety.

\section{Philosophy and history of engineering}

Modern building engineering is founded on a base of craft knowledge and rules of thumb together with the application of science (Blockley, 1980). Early builders were often proficient in the mathematics and science of their time as well as the crafts associated with building. Indeed the Roman, Marcus Vitruvius, stated “...Architects who have aimed at acquiring manual skill without scholarship have never been able to reach a position of authority to correspond to their pains, while those who relied only upon theories and scholarship were obviously hunting the shadow, not the substance. But those with a thorough knowledge of both, like men armed at all points, have the sooner attained their object and carried authority with them" (Blockley, 1980).

Despite the fact that the profession has become increasingly regulated, rules of thumb and approximations remain fundamental aspects of the profession allowing safe and appropriate designs to be economically produced that will satisfy all envisaged service conditions (Blockley, 1980).

The training and development of structural design engineers has changed with the advent of computerised analysis and design software packages. Previously, engineers entering design offices gained a feel for the building by carrying out repetitive calculations by hand "number crunching" under the direction of experienced engineers (Blockley, 1980). Whilst acknowledging the positive benefits and opportunities that computing has brought to structural engineering, Dr David Brohn questions, "how are the skills of structural modelling, hard won by designers before computers existed, to be transferred to the new generation of young engineers in training?" (Brohn,2006).

\section{Process of design}

Design ultimately revolves around solving the problem of "bad fit" (Alexander, 2000). Interestingly, it is much easier to detect bad fit than a good fit and to identify poorness of fit before too much detail is added (Simon, 1982) 
A series of choices are made to overcome the problems of bad fit (Simon, 1982; Blockley, 1980). In essence, 'design is a creative process of adequate problem solving' (Wilpert, 2007). Experiences are of significant value to our problem solving process as they show what the impact of our actions will be under known conditions. The choices and changes we make to a design are predominantly by trial and error but guided by experience. The human mind is also able to use experience to recognise patterns and situations that a computer is unable to achieve (Simon, 1982).

It is important to recognize that design is an iterative process (Alexander, 2000; Wilpert, 2007) and '...almost without exception, design concepts do not appear, in their totality, all at once'(Goldschmidt,1994).

\section{The impact of the digital era}

Digital technologies have profoundly affected the way we work. Engineers and designers can become preoccupied with accuracy at the expense of practical solutions(Zhou et al, 2012).

Karl Weick (1985) questions the effectiveness of people using computers. 'People using information technologies are susceptible to cosmology episodes because they act less, compare less, socialize less, pause less, and consolidate less...As a result, the incidence of senselessness increases' (Weick,1985).

Researchers have identified that 'digital systems do not encourage the active challenging of assumptions' (Zhou et al,2012). For young engineers, who lack the experience to challenge the output, this can lead to a feeling of omniscience (Weick, 1985) and subsequently to 'mindlessness' (Zhou et al, 2012)

The problem of consolidating is identified by Whyte (2013), where designers being studied, commented that errors were usually identified when a new engineer joined the team and saw the project with a 'fresh set of eyes' (Whyte, 2013, p51). This is analogous to the discovery of new scientific paradigms by scientists new to the field (Kuhn, 2012) and is particularly dangerous when inexperienced engineers working in isolation lack the opportunity, or inclination, to discuss their work with colleagues.

\section{Visualisation and visual imagination}

Improved visualisation is often propounded as being one of the major benefits of the BIM process (Eastman et al, 2011; 2010; Kiviniemi et al, 2011). A serious weakness with this argument, however, is that it fails to acknowledge that the interpretation and understanding of visual images is largely dependent upon our own experiences.

Hanson (2010) demonstrates this anomaly efficaciously by citing two $16^{\text {th }}$ century astrologers who are asked what they see when they witness the dawn. Tycho Brahe, followed the religious dogma of the day, believed that the earth formed the centre of the universe and everything revolved around the earth. His observation was that the sun was rising above the horizon. When asked the same question, Johannes Kepler, who accepted Copernicus's understanding of the cosmos, would see the horizon 
dipping below the sun. If asked to draw what they saw, both astrologers' drawings would be identical indicating that what they 'saw' was more than an implant on their retina but an interpretation based on previous experiences and understanding.

All too often the model is simply a representation of the design and arguably does not promote or encourage visual imagination or perception, which are required to facilitate the discovery of knowledge (Jessop, 2008).

\section{Digital developments in health and safety}

The processes involved in the construction industry are due to be transformed with the advent and growing use of BIM necessitating a greater requirement for sharing information through digital data bases and parametric 3D models. If this technology can be linked successfully with the planning and implementation of health and safety (H\&S), it has the potential to deliver significant benefits to the industry.

Kiviniemi et al (2011) have considered the subject extensively and have identified four main areas where they suggest BIM could be advantageous in improving health and safety:

1. BIM based safety planning including site layouts and fall prevention

2. Risk analysis and evaluations, either visually or automatically generated.

3. 3D visualisations to improve communication eg. Site inductions

4. BIM based information on products, etc.

The automatic checking of models to identify slab edges and the requirements for safety barriers have been developed by Kiviniemi et al (2011) and Zhang et al, (2013)

One possible drawback of automated tools is that engineers may stop being proactive in managing safety and rely too much on the tool to highlight safety needs.

\section{Development of new digital tools to address industry issues}

From the preceding sections it is evident that the industry faces several major obstacles in improving the DfS aspects of its work. As a consequence of the emergence and widespread use of computerised analysis and drawing tools, elements of the industry have been moving away from their traditional roots and philosophies. One such area is the training and development of engineers at the start of their working lives. Through the use of new technologies and processes such as BIM, these engineers can be making significant strategic contributions to projects during the early phases of the design process. Without appropriate training and experience the decisions these engineers make can have serious impacts on the safety of the construction works and the operations of the artefacts being designed. With the tendency to develop digital safety tools based on the capability of the software rather than the needs of the industry, little is being done to rectify the root causes of the problems, instead quick fix tools are developed that deal with the symptoms. 
A generation ago, young engineers often developed a practical approach to building design by two distinct approaches: firstly, being exposed to regular site visits and prolonged periods resident on site, either working for the client or on exchange to a contractor. Secondly, by operating as part of a team with more experienced engineers in an environment that encouraged the attributes noted by Weick (1985); triangulation, affiliation and consolidation. Operating in this method assisted the development of engineers by acquisition of information and experience which could, over a period of time, be transferred into knowledge. Formal and informal conversations with fellow designers, draughtsmen, site engineers and tradesmen formed a fundamental component of their development.

To overcome the deficiencies noted above all the facilities attributable to modern digital technologies must be employed whilst not making the prevalent mistake that a $3 \mathrm{D}$ visualization solves most, if not all of, the problems. The ability to view a design in $3 \mathrm{D}$ has the distinct advantage of allowing inexperienced engineers to understand the spatial relationship of elements without the need to elucidate 2D plans and sections. However, contrary to the thoughts of many in the industry, a 3D model does not impart information or knowledge to a new engineer who lacks experience.

Utilizing the attributes associated with digital technologies, including augmented and virtual reality as well as the BIM process, the following section illustrates a potential framework for a DfS tool that could be developed to address some of the key issues mentioned above. The suggested characteristics of the tool are specifically intended to increase the training, development and knowledge acquisition of newly graduated engineers using technologies they are comfortable with.

The identification of hazardous operations; frequently, young engineers are unaware of the hazards created by the forms of construction they select in the design process. For instance, an inexperienced engineer is probably unaware of the requirement for prolonged periods of working at height to create formwork with downstand beams or the hazards associated with the demolition of post-tensioned concrete structures. Several tools have been developed that identify hazards (Zhang et al, 2013; Kiviniemi et al, 2011) and whilst successful in their objectives these tools do not incorporate the additional characteristics set out below which are considered important to the development of engineers.

The explanation of the hazards; once identified, an explanation of the hazard should be provided in order to educate the engineer. This element of the tool could adopt a multimedia approach utilising a mixture of text, video, augmented and virtual reality. This process is fundamental in providing the experiences that are often lacking in the modern design office. A short interview with a formwork carpenter and a short film showing the work being carried out can explicitly demonstrate the hazards that he may face constructing formwork at height. Statistical information relating to falls by carpenters can reinforce the experience.

Suggested alternatives; It is imperative that engineers are provided with sufficient information to enable them to make appropriate, sound and reasoned decisions. For this to be actualized, suitable alternative design solutions should be presented along 
with the hazards that these alternatives could create. Health and safety must be a major consideration in the design process but it should be acknowledged that it is not the only factor. Therefore, alternative less hazardous forms of construction should not be automatically incorporated into the design.

The identification and explanation of hazards together with the suggestion of alternatives provides a solution to the issue of consolidation noted earlier (Whyte, 2013). The development of the e tool will require significant inputs from experts within the industry. The subsequent outputs of these experts, processed by the tool, will provide the fresh set of eyes that are often lacking in the modern work environment.

The dissemination of information relating to construction processes; Design engineers are often spending less time on construction sites and may not be aware of the processes required to make their designs real. A series of multimedia tutorials demonstrating construction techniques would increase the engineers understanding and improve their ability to identify hazards. For example, a tutorial illustrating the construction, and pros and cons, of different types of pile foundations should aid the designer in the selection of piles for future projects.

Advice on the information required to mitigate residual risks; It is inevitable that certain residual hazards may remain in the completed design and specific information will be required by the contractor and owner to mitigate such risks. A failing of designers is that appropriate information is not always passed to the relevant organization. The tool should identify hazards where information should be passed to others, highlighting this to the designer clearly indicating the type of information required. For instance, if a cantilever is incorporated into a design or complex bracing systems are used, an assumed sequence of erection should be clearly identified to the contractor to prevent structural collapse in the temporary condition.

Ease of use; A DfS tool should sit alongside the digital toolbox already at the disposal of designers. Due to the iterative nature of design it is anticipated that a tool could be repeatedly used throughout the design process. The earlier use will allow fundamental changes in construction forms to be considered whilst the later use will focus much more on smaller elements. By encouraging repeated use of the tool, the engineer will be able to identify the $\mathrm{H} \& \mathrm{~S}$ implications of design changes, a process that is often neglected.

The essence of the tool is that it educates and trains engineers, filling the gaps in experience that are developing as a result of changes brought about by the use of digital technology. Paradoxically, digital processes such as BIM will be used as a framework for the tool. The information stored within the parametric building information models (BIMs) could be manipulated to identify hazards and provide links to the supporting files. The scope for the tool is potentially limitless, allowing provision for inclusion of all the design disciplines 


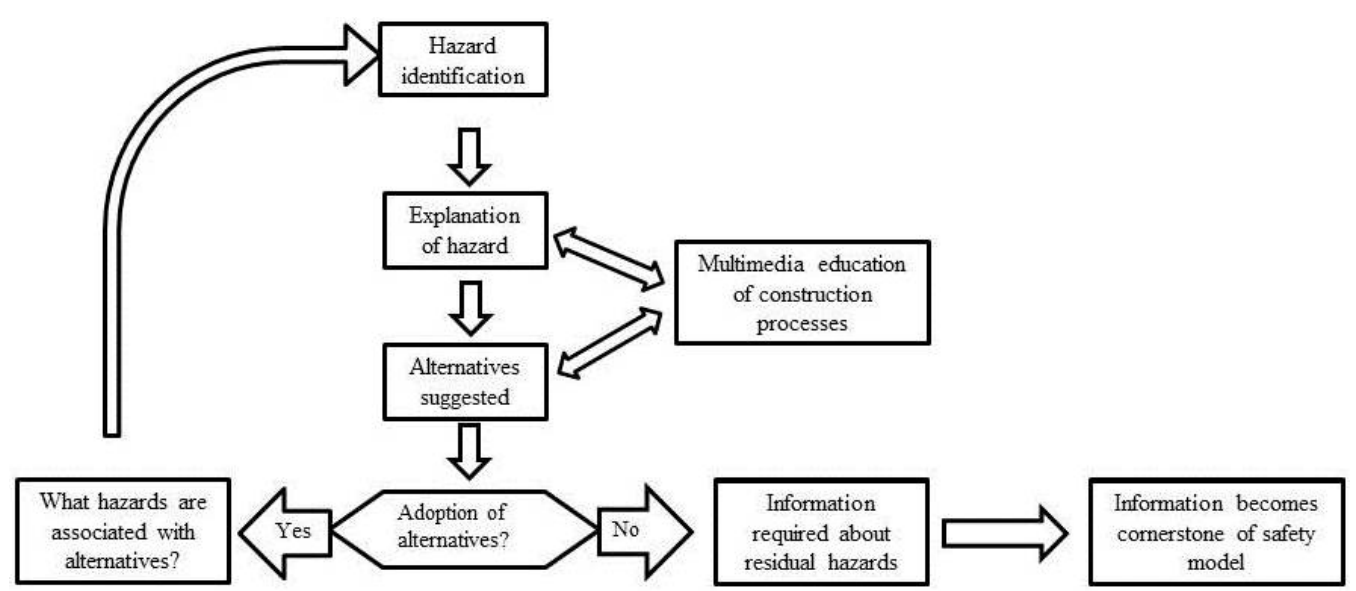

Figure 1. Suggested Framework for development of the DfS tool.

The dimensions of BIM are being expanded with 4D time models and 5D cost models. To date, little is being discussed that relates to a safety model but it is envisaged that a well-designed DfS model would have the potential to be developed further into a project safety model. If successful a project safety model would act as repository for all project safety information and educational requirements from the early design stage through construction and operation to decommissioning. It is important to note that a project safety model should be a live and evolving model that is accessed and utilised by everyone associated with the facility throughout the project life cycle, far exceeding the requirements of the CDM regulations (HMSO, 2007), that are in operation within the United Kingdom.

This framework is currently under validation by getting feedbacks from the industry and a prototype tool will be developed after this validation phase.

\section{Conclusions}

The rapid development of digital technologies has inordinately altered the operating procedures of building design offices. Engineers no longer undertake repetitive manual calculations that gave them an understanding, or feel, for the structure and an ability to challenge rogue results. On the contrary, graduate engineers are now able to build complete structural analysis and building models relatively quickly, but it is questionable whether they have the experience to understand the output of such models or if they enter a world of mindlessly assuming the outputs are correct.

The much propounded opinion that having the ability to see 3D models of the facility improves understanding is questionable as cognition is based upon experiences which are often left wanting. The isolated nature of digital working is arguably leading to a reduction of the tacit knowledge held by older and more experienced engineers being incorporated into designs.

The development of an interactive digital teaching tool that sits alongside the analysis and modelling software should be able to provide a repository for this knowledge and allow its dissemination to less experienced engineers. A multimedia 
approach may be required with the resulting information creating the foundation of a project safety model.

\section{References:}

Alexander, C., (2000), Notes on the synthesis of form, Harvard University Press, London.

Blockley (1980), The nature of structural design and safety, Ellis Horwood Ltd, Chichester.

BrohnD., (2006), Post-Graduate Training Course 'Understanding Structural Behaviour' Organised for the Institution of Structural Engineers, 2006. [online] Available at: http://www.newparadigms.co.uk/downloads/USBCourseReview.pdf [Accessed 26 August 2013]

Eastman,C., Teicholz,P., Sacks, R., Liston, K.,(2011),BIM Handbook. New Jersey, John Wiley and Sons.

Gambatese, J., and Hinze, J., (1999), Addressing construction worker safety in the design phase: Designing for construction worker safety. Automation in Construction, 8(6), pp. 643-649.

Goldschmidt, G., (1994), On visual thinking: the viz kids of architecture, Design Studies, vol.15, no.2 pp. 158-174

Hanson, (2010), Patterns of discovery, An Inquiry into the Conceptual Foundations of Science, Cambridge University Press, Cambridge

Haslam,R.A., Hide,S.A., Gibb,A.G.F., Gyi,D.E.., Pavit,T., Atkinson,S., Duff,A.R., (2005), Contributing factors in construction accidents, Applied Ergonomics, vol.36, pp401-415.

HMSO, (2007), Construction(Design and Management)Regulations 2007, Her Majesties Stationary Office, London

Jessop, M., (2008), Digital visualization as a scholarly activity, Literary and Linguistic Computing,vol. 23, no.3, pp.281-293

Kiviniemi, M., Sulankivi, K., Kähkönen, K., Mäkelä, T., and Merivirta, M., (2011), BIM based safety management and communication for building construction. Research notes 2597VTT Technical Research Centre of Finland

Kuhn, T., S., (2012), The structure of scientific revolutions, University of Chicago Press, London

Simon, (1982), Sciences of the artificial. The MIT Press, Cambridge MA

Weick, (1985), Cosmos vs Chaos: Sense and nonsense in electronic contexts, Organisational Dynamics, vol. 14, no. 2, pp51-64

Whyte, J., (2013), Beyond the computer: Changing medium from digital to physical, Information and organization, vol. 23, pp. 41-57

Wilpert, B., (2007), Psychology and design processes, Safety Science, vol. 45, pp.293-303.

Zhang, S., Teizer, J., Lee, J., Eastman, C.M. and Venugopal, M., (2013),. Building Information Modeling (BIM) and Safety: Automatic Safety Checking of Construction Models and Schedules. Automation in Construction, 29(0), pp. 183-195.

Zhou,W., Whyte,J., Sacks,R., (2012), Construction safety and digital design: A review, Automation in Construction, vol.22, pp.102-111. 